Supporting Information for bm0607933

\title{
New Biodegradable Thermogelling Copolymers Having Very Low Gelation Concentrations
}

\author{
Xian Jun Loh, ${ }^{\dagger}{ }^{\ddagger}$ Suat Hong Goh, ${ }^{\dagger}$ and Jun $\mathrm{Li}^{*}{ }^{\dagger, \S}$ \\ ${ }^{\dagger}$ Institute of Materials Research and Engineering, National University of Singapore, 3 \\ Research Link, Singapore 117602; \\ $\ddagger$ Department of Chemistry, Faculty of Science, National University of Singapore, 3 \\ Science Drive 3, Singapore 117543; \\ $\S$ Division of Bioengineering, Faculty of Engineering, National University of Singapore, \\ 9 Engineering Drive 1, Singapore 117576
}




\section{Experimental:}

Gel samples (5 wt \%) were cast on glass coverslips $(1.5 \mathrm{~cm}$ x $1.5 \mathrm{~cm})$. The glass coverslips were placed on a temperature controlled stage. Optical microscopy micrographs were taken with a Nikon microscope attached with a CCD camera. The images were analyzed using ImagePro Plus software. For each sample, at least 100 different measurements of the particle size were made. Values were reported as mean \pm standard deviation. 
Figure S1. EPH1 gel $(5 \mathrm{wt} \%)$ at $20{ }^{\circ} \mathrm{C}$ (clear gel state) and $80{ }^{\circ} \mathrm{C}$ (turbid sol state). (Scale $\operatorname{bar}=30 \mu \mathrm{m})$
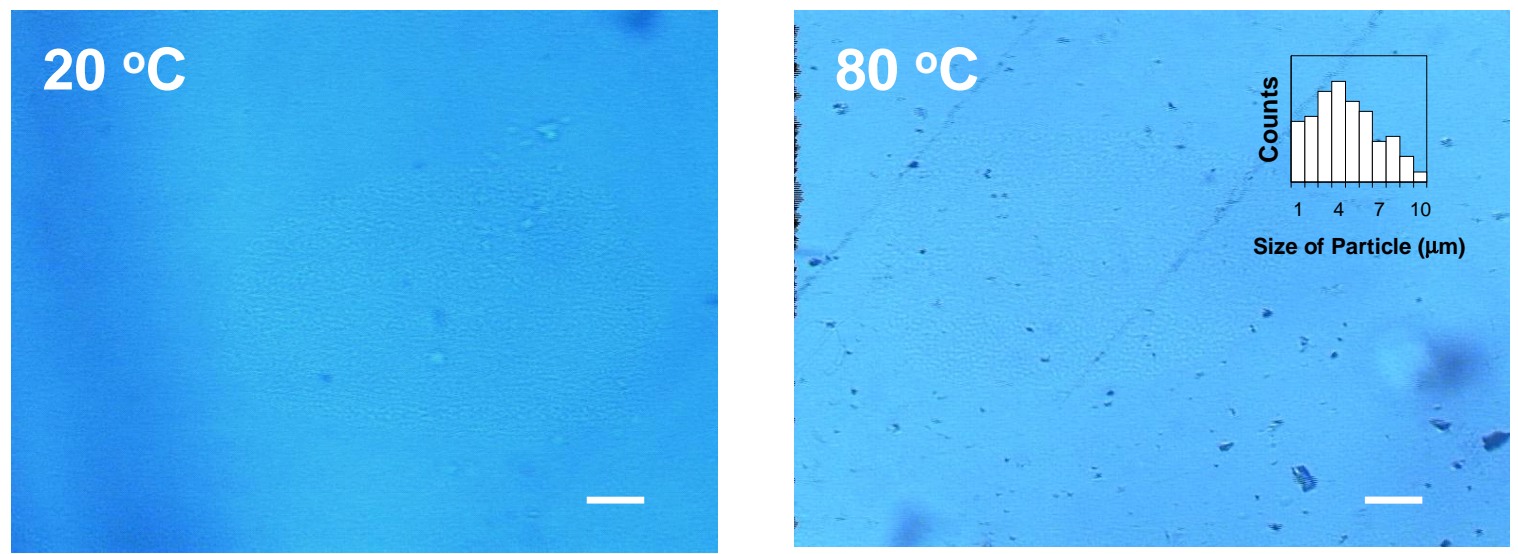
Figure S2. EPH2 gel $(5 \mathrm{wt} \%)$ at $20{ }^{\circ} \mathrm{C}$ (clear gel state) and $80{ }^{\circ} \mathrm{C}$ (turbid sol state). (Scale $\operatorname{bar}=30 \mu \mathrm{m})$
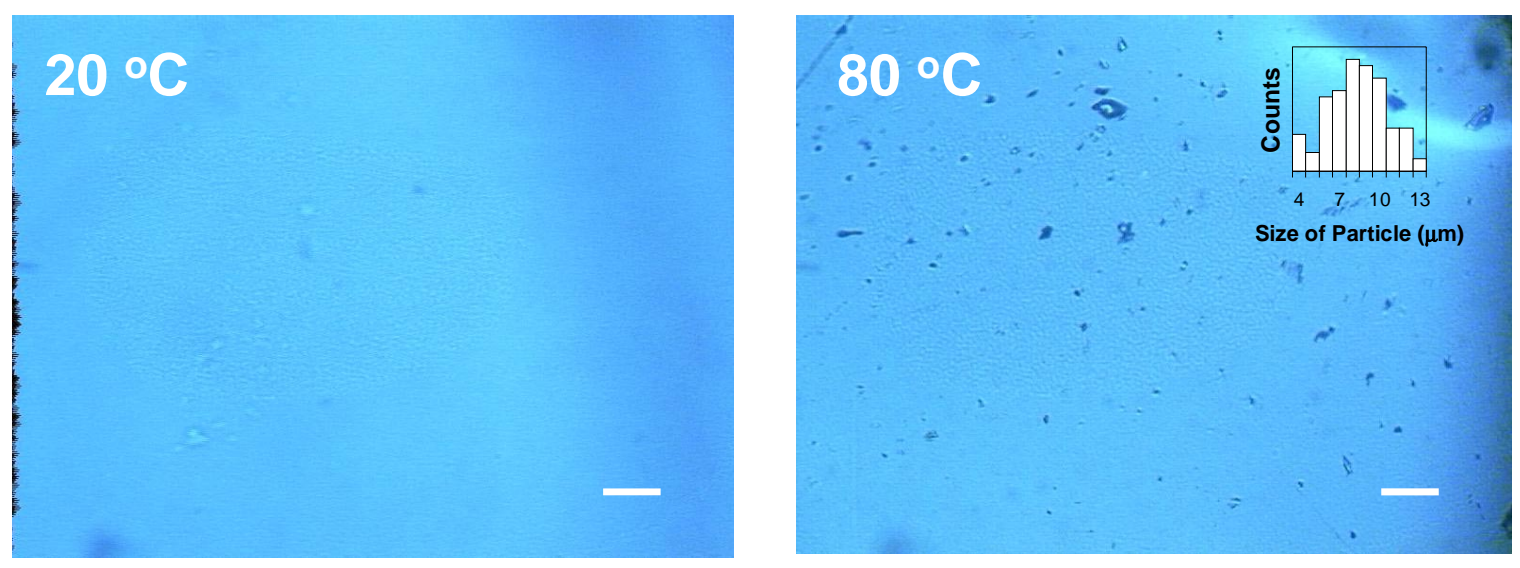
Figure S3. EPH3 gel $(5 \mathrm{wt} \%)$ at $20{ }^{\circ} \mathrm{C}$ (clear gel state) and $80{ }^{\circ} \mathrm{C}$ (turbid sol state). (Scale bar $=30 \mu \mathrm{m}$ )
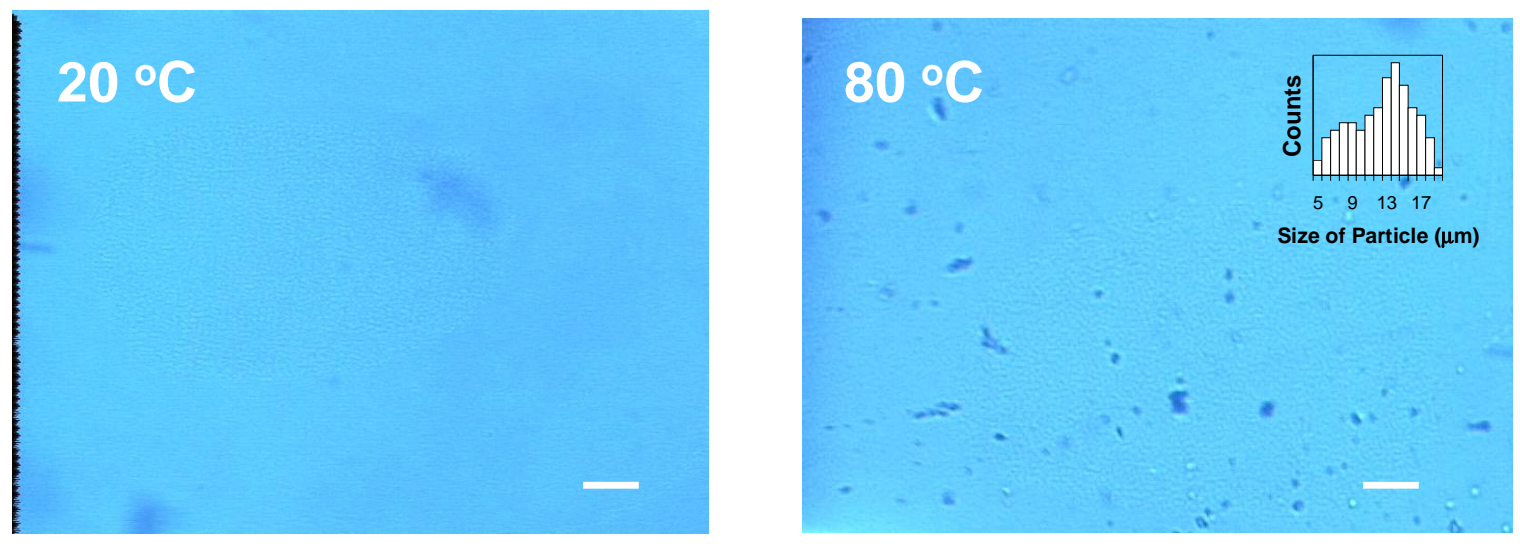